\title{
La tela sobre la materia: lenguaje y materialidad en la novelística de Jorge Eduardo Eielson
}

\author{
Pamela Medina García ${ }^{1}$
}

Resumen. El objetivo de esta investigación es identificar la forma en la cual el lenguaje se ha convertido en una preocupación persistente en la obra del artista peruano Jorge Eielson (1914-2006), la misma que le ha otorgado un carácter interdisciplinario a sus representaciones. Es decir, la consciencia del lenguaje transita y vincula las disciplinas desarrolladas por el artista entre las que destacan poesía, novela o artes plásticas. Es precisamente en las dos últimas en la cual se detendrá nuestro análisis, las novelas El cuerpo de Giulia-no (1971) y Primera muerte de María (1988) y la serie matérica Paisaje infinito de la costa del Perú (1960-1980). Para esto, proponemos un acercamiento interdisciplinario en dos tramos. En el primero, abordaremos los aspectos narratológicos y los vinculados a la filosofía del lenguaje en El cuerpo de Giulia-no para determinar que los personajes que Eielson construye son sujetos del lenguaje. En el segundo, establecemos los diálogos de Primera muerte de María con las obras plásticas a propósito de un cuestionamiento a la escritura y a la representación del lenguaje. Nuestra investigación nos permitirá concluir que Jorge Eielson es un autor consciente del lenguaje que, a partir de su cuestionamiento y su nivel autorreflexivo, tensiona y diversifica el registro escritural y el máterico.

Palabras clave: lenguaje; materia; novela; Eielson; interdisciplinariedad.

\section{[en] Fabric covering matter: language and materiality on the fiction of Jorge Eduardo Eielson}

\begin{abstract}
The objective of this paper is to identify the way in which language has become a persistent concern in the works of the Peruvian artist Jorge Eielson (1914-2006), it is this concern that bestowed an interdisciplinary nature to his works. Specifically, the conscience of a language travels and links the disciplines developed by the artist like poetry, novels or fine arts. It is precisely in the last two where we will focus our analysis, the novels El cuerpo de Giulia-no (1971) and Primera muerte de María (1988), and the matter painting series Paisaje infinito de la costa del Perú (19601980). In order to do this, we will work in a two-step interdisciplinary approach. In the First, we will tackle both the narrative and the philosophical aspects in El cuerpo de Giulia-no to establish that the characters built by Eielson are subjects of the language. Second, we will confront the dialogues of Primera muerte de María with the fine arts so we can question both the writing in general and the representation of a language. Our research will allow us to conclude that Jorge Eielson is an artist aware of the language, and it is from here and from his self-reflective nature, that he braces and diversifies the written and matter painted work.
\end{abstract}

Keywords: language; matter; novel; Eielson; interdisciplinarity.

Sumario: 1. Introducción. 2. El cuerpo de Giulia-no y el despertar de la consciencia del lenguaje. 3. La materialidad del lenguaje en Primera muerte de María. 4. Conclusión.

Cómo citar: Medina García, P. (2021) La tela sobre la materia: lenguaje y materialidad en la novelística de Jorge Eduardo Eielson, en Anales de Literatua Hispanoamericana 50, 367-379.

\section{Introducción}

En la tradición literaria peruana, Jorge Eduardo Eielson (1914-2006) no es precisamente reconocido como narrador. Desde la década del cuarenta, estuvo emparentado con la poesía y las artes plásticas con obras

\footnotetext{
${ }^{1}$ Universidad Peruana de Ciencias Aplicadas. Perú.

E-mail: cinnamonpamg@gmail.com
} 
como el poema largo Canción y muerte de Rolando (1943) y las esculturas y móviles expuestos en 1948 en La Galería de Lima. Sin embargo, es en la siguiente década, la misma en la que se gesta en Perú la narrativa urbana de Enrique Congrains y Julio Ramón Ribeyro, donde inicia la escritura de su primera novela El cuerpo de Giulia-no. Al formar parte de la generación del cincuenta, una promoción caracterizada por su producción conjunta, el autor también integra este grupo de narradores de acuerdo con lo que la crítica literaria italiana Giovanna Minardi señala como "el espíritu común de renovación estilística y temática que caracteriza la literatura peruana a partir de 1945" (2016: 109). Eielson, al igual que Ribeyro o Congrains, transversaliza sus novelas con un espíritu renovador; sin embargo, a diferencia de ellos, afinca su carácter experimental para favorecer su representación de Lima y, en ella, de su crítica al lenguaje.

\section{El cuerpo de Giulia-no y el despertar de la consciencia del lenguaje}

Entre 1953 y 1957, Jorge Eduardo Eielson escribió su primera novela El cuerpo de Giulia-no (1971)2, momento que coincide con la creación de los denominados "poemarios romanos"3 que, entre otros aspectos, asumen en su construcción la indagación de la palabra y en general la problematización del lenguaje que inició con el poemario experimental Tema y variaciones (1950) ${ }^{4}$. La novela vería la luz hacia 1971 en México y en su construcción, o más precisamente en su fragmentación, no sería ajena a las indagaciones de las obras antecesoras. El hecho inicial, sobre el que aparentemente se desenvuelve la historia, es la aparición del cuerpo sin vida de Giulia, bella joven italiana, que en la morgue de Venecia es contemplada con impaciencia por Eduardo, protagonista de la novela y personaje al que se encontraba sujeta. Giulia ha muerto y el drama de Eduardo, su amante, es la imposibilidad de recuperar el cuerpo y definir con palabras la extraña relación sentimental que mantuvo con ella. Suman a esta tensión en la novela la reiterada intervención de personajes como el tío Miguel, Giuliano (deconstruido en la obra como "Giulia con ano") o Mayana, quienes atraviesan con facilidad espacial y temporal la historia, indistintamente entre Monteyacu, aparente paraje amazónico perdido, e Italia, o entre la infancia y la juventud. El discurso asume en sí mismo dichos quiebres en anacronías como analepsis y prolepsis. Además, este integra elementos de los discursos teatrales y cinematográficos que enrarecen su composición. A su vez, es posible identificar tramos maravillosos o contrafácticos ${ }^{5}$ (Ramírez 2001: 27) que son integrados en la dinámica de la diégesis. Todo esto plantea en la novela un nivel de fragmentación que, sobre los 22 capítulos del discurso, nos exige detenimiento y asociación en una historia configurada a la voluntad del narrador, autodiegético ${ }^{6}$. Este no solo tiene el rostro del narrador personaje, al mismo tiempo, parece poseer y no poseer el dominio del lenguaje con el que dispone la diégesis. Eduardo se convertirá así en el personaje que articula y manifiesta estas variantes: el que, a su vez, se afirma y desestabiliza con facilidad ante las peripecias de la historia. En el desarrollo de la novela, estos aspectos son las condiciones en las que se evidencia la consciencia del lenguaje y las formas en la que este es cuestionado.

Desde la infancia, Eduardo es un sujeto marcado por el pensamiento reflexivo del lenguaje. Esta visión recorre todas sus prácticas y la forma en la que se relaciona con los demás. Una de ellas es la manera en la que se define a través de la diferencia, sobre todo, de lo que su tío Miguel no es capaz. Descrito como un ser grotesco y abusivo que ocasiona repulsión, características que lo alejan de Eduardo, este, además, representa a su tío como un personaje desprovisto de agencia con las palabras:

Porque él podía jugar con la vida de los indios, apoderarse de sus tierras, juntar monedas de oro en un banco de provincia, emborracharse como un odre, insultar a todo el mundo, pero no podía jugar con las palabras, no podía afrontarme en esta partida de revancha en la que yo toda la vida habría de ganarle, aun después de muerto. (Eielson, 1971: 16)

\footnotetext{
${ }^{2}$ El cuerpo de Giulia-no también se denominó una performance-instalación realizada en la Bienal de Venecia en 1972.

${ }^{3}$ Denominamos así a los poemarios escritos durante la estancia de Eielson en Roma, en resonancia de la selección editada por Martha Canfield de la poesía de nuestro autor denominada Poeta en Roma.

${ }^{4}$ En Tema y variaciones (1950), poemario de raigambre vanguardista, se apartan las anécdotas para encontrar solo palabras que se confunden en sonidos o desmaterializan el objeto. En ese sentido, entendemos este poemario como un conjunto de ejercicios a partir de su materialidad o plasticidad que conducen al desarrollo de una consciencia del lenguaje desde dos motivos.

${ }^{5}$ Sergio Ramírez Franco acuña "contrafáctico" como término más preciso a fantástico, maravilloso o mágico, que a su vez le permite dimensionar los mundos alternos y heterogéneos propuestos por Eielson (2001: 27).

${ }^{6}$ Gérard Genette define al narrador autodiegético cuando este es el protagonista del relato (Genette 1989: 299-301).
} 
La hostilidad con la que es descrita el tío Miguel puede desenvolver su ausencia de humanidad y sensibilidad (juega con la vida de los indios), o su incapacidad de comunicarse. Mientras menos sensible, más ajeno es a las palabras o a todo lo que se puede acceder con ellas. En cambio, en su falta de contención emocional ("aun después de muerto"), Eduardo, al reconocerse como un sujeto de palabras, y al vincular a Miguel con una cualidad inversa, también incide y le da forma a su valor lingüístico, una operación que asimila la reflexión de Ferdinand de Saussure sobre el valor de la palabra "su más exacta característica es la de ser lo que los otros no son" como tibio es lo que no es frío ni caliente (Saussure, 1945: 141) ${ }^{7}$. En este sentido, la más exacta característica de su tío Miguel es la de ser lo que él no es. Dicho de otro modo, todo lo que es su tío no es Eduardo, la hostil descripción que el joven va enumerando en el transcurso de la novela. Es esta probablemente una práctica preliminar a la designación que construirá para Giulia, entre ella y Giuliano. Con el mismo tono con el que describe al tío Miguel, Giuliano es un personaje que produce aversión en la vida de Eduardo. El joven empresario heladero, hijo de un italiano y una chuncha, representa una mente capitalista y desleal que contrasta con la personalidad sensible del protagonista. En su primera aparición, propiciamente cortejando a la mujer del otro, Eduardo lo define "positivamente por su contenido" (1945: 141) para luego ser el contraste con el que se define Giulia: "Una terrible cosa que sudaba en pleno invierno y se llamaba Giuliano. Es decir Giulia con ano" (Eielson, 1971: 17). Ambos personajes son construidos en su diferencia, Giulia, al no ser Giulia, es Giuliano, un ser "incurable" con "ano, con panza, con zapatos lustrados, con millones" (1971: 18). Planteado así, la formulación Giulia-no, que nombra a la novela, es el anclaje del deseo de Eduardo por mantener incólume el cuerpo de su amada, lejos de perturbaciones que deforman su recuerdo y el cuerpo mismo; además, es el valor lingüístico que la define "negativamente por sus relaciones con los otros términos del sistema" (Saussure, 1945: 141). Dicho de otro modo, Giulia no es Giuliano o no Giulia es Giuliano, como en la designación del tío Miguel, porque así parecen identificarse los personajes en esta novela, su ritmo de asociación pasa por lo que el protagonista no quiere ser o no desea para sí, hasta una operación del lenguaje que se presenta del lado inverso.

La consciencia del lenguaje es despertada en Eduardo a partir de la muerte de Giulia. En la impresión generada frente al cuerpo de la joven, se reconoce incapaz de recuperarlo con palabras: "Pero mis palabras no podrían nunca formular ese vacío, puesto que ahora tu cuerpo mismo depende de estas palabras [...]" (Eielson, 1971: 11). Eduardo es un sujeto del lenguaje, sabe plenamente su imposibilidad y, a su vez, que él mismo puede ser una construcción de este círculo vicioso en el que se encuentra inmerso. Así lo evidencia líneas posteriores donde el recuerdo de Giuliano y la hacienda de San Ramón lo sume en una retahíla de preguntas que constituyen una forma de reconocerse y reconocer a los demás, y confronta su memoria para diluirse en las mismas preguntas desde las cuales pretendió afirmarse: "¿O tampoco esto era cierto, y Mayana como Giuliano, como mi madre, como tú misma, habrían de hacer de mí un muñeco ruin y destripado? ¿O todo eso se debía sólo al insondable tejido verbal que siempre había alimentado mi existencia y que se había convertido en ella misma?" (1971:21). Ser un "insondable tejido verbal" llena de preguntas la existencia de Eduardo y alimenta de cuestionamientos la novela de Eielson por tratar de aprehender lo inexplicable y lo ausente. ¿Cómo recuperar con palabras el cuerpo que se ha ido?, esa parece ser una de las incesantes interrogantes del protagonista: "Me pregunto si tu perfil y tus piernas de pájaro no serán el perfil y las piernas de un ser humano que mi imaginación confunde con el perfil y las piernas de un pájaro. Trato de recordar. Las palabras, cierto, no me ayudan" (34). En un punto de contacto, la desventura de Eduardo puede ser la misma del mito de Orfeo y Eurídice. Cuando Orfeo, arrancado por el temor de no tener a Eurídice, voltea a mirarla, no solo quiebra la condición que le había sido impuesta por el señor que gobernaba los desapacibles reinos de la sombra, además, la conmina nuevamente a la muerte ${ }^{8}$. El deseo y la reafirmación de su presencia solo lo sitúa frente a la forma sin rostro de la ausencia. Maurice Blanchot alude y desenvuelve el valor simbólico de este mito, específicamente, con el siguiente enunciado: "Escribir comienza con la mirada de Orfeo" (Blanchot, 2002: 159). El propósito de esta frase es referirse a la manera cómo en la obra se asume

\footnotetext{
${ }^{7}$ Para Saussure en la palabra los valores se definen, no por ideas dadas de antemano, valores que emanan del sistema, sino porque estos son "son puramente diferenciales", es decir, definidos no positivamente por su contenido, sino negativamente por lo que no es en relación con otros términos. En ese sentido, señala Saussure que su más exacta característica es la de ser lo que los otros no son. (Saussure, 1945: 141).

${ }^{8}$ Esta es una expresión que Michel Foucault en el ensayo dedicado al pensamiento de Maurice Blanchot denominado "El pensamiento del afuera", que forma parte del libro Entre filosofía y literatura. El propósito de esta es aludir al ser mismo del lenguaje como aquél que se desvela como transparencia recíproca del origen y de la muerte en la cual no hay una sola existencia que no reciba la promesa amenazadora de su propia desaparición y de su futura aparición (Foucault, 1999: 319).
} 
una soledad esencial. Dar la muerte, a través de la mirada de Orfeo, se convierte en una condición para la escritura porque es el descubrimiento de la distancia interpuesta entre el sujeto y su objeto o la forma en la que este se encuentra cubierto de ausencia. Para Michel Foucault, en consonancia con Blanchot, el "olvido asesino de Orfeo" ejemplifica un carácter del lenguaje. La vuelta del rostro es descubrir que ese lugar solitario, que crece en uno, evidencia, a su vez, cómo el lenguaje cubre o disimula una ausencia: sin sujeto, sin dios, sin personaje, rostro sin expresión que alivie esa impaciencia (Foucault, 1999: 314). El olvido entonces abre una grieta, un espacio neutro, en el que ninguna existencia puede afirmarse, y un abismo entre el yo y las cosas, como constatando quizá que en el deseo de recuperación de esa presencia solo hay lugar para el desposeimiento del objeto. Eduardo sin Giulia, Orfeo sin Eurídice, la ausencia de la amada, o la pérdida de la certeza de su cuerpo, en ambos casos, son objeto de un episodio en el cual el ser del lenguaje se descubre a partir de la muerte o la desaparición del sujeto.

Aquello que despierta la amada ausente son los eslabones de una cadena donde el lenguaje se haya revelado y cuestionado. No obstante, antes de ser el objeto principal de su problematización, existe un aspecto inicial que atraviesa esta cadena en diversos pasajes de la novela y al cual está sometido el protagonista. Previa a la consciencia del lenguaje, desplegada en Eduardo, se gesta un presupuesto inefable e inexplicable en el vínculo (aparentemente de amor) que lo unió a Giulia. Uno de estos momentos es la descripción del acto amatorio:

En el fragor de la noche todo nos estaba permitido, hasta quitarnos nuestro cuerpo por momentos y volvernos una sola criatura celeste, un solo resplandor sobre el lecho. Aunque luego, durante el día ¿recuerdas? El silencio cayera entre nosotros como un manto plomo. Como las víctimas del Vesubio -pobres larvas convertidas en piedra, carbón, metal orgánico, momias de la vida diaria- como las criaturas quemadas por la lava y la ceniza, nuestras palabras en adelante no emitirían sino silencio. ¿Trasmutación divina? ¿Sabiduría completa? ¿O total ignorancia? ¿Para qué decir nada entonces? ¿Para qué escribir? (Eielson, 1971: 87)

Convertidos en piedra, el amor suspende todo acto de comunicación, se asemeja a un estado de enmudecimiento incapaz de ser alcanzado por las palabras. Oportunamente, en un proposición del Tractatus lógico-philosophius, Ludwing Wiitgenstein señalaría que "de lo que no se puede hablar hay que callar", pues para el filósofo lo inexpresable, y digno de silencio, pertenece al terreno de lo místico, ya que el método filosófico demostraría que, cuando se pretende decir algo metafísico, sus proposiciones no le darían significado a todos sus signos (2010: 131-132). Visto de esta manera, nos gustaría pensar que el acto amatorio de Eduardo con Giulia es inicialmente inefable ya que no se puede explicar con palabras -sin correspondencia común, cotidiana o terrenal- porque está más próximo a ser una experiencia divina ("volvernos una sola criatura celeste, un solo resplandor sobre el lecho"). Ante esta condición, revestir todo de silencio es tratar de convertir la experiencia en intraducible o inexplicable, un terreno impenetrable para la palabra, pero favorable para la sensibilidad del cuerpo; precisamente ese que ya no está, y que en el intento de su recuperación, se ha descubierto que el artificio verbal resulta inútil. "Para qué escribir", nos diría Eduardo.

Una vez más, frente al cuerpo inerte, el joven es objeto de una serie de interrogantes a sí mismo que pretenden aterrizar o darle nombre a la experiencia vivida con Giulia: "Cámara frigorífica y sudario ¿cómo reconocerte? ¿Soy pariente tuyo, esposo, novio, prometido, amigo? ¿Qué cosa fuimos, Dogaresa? ¿Amantes solamente? ¿Amantes realmente? ¿Hablamos acaso del amor alguna vez? ¿Quién dijo nunca "te amo"? ¿Me dijiste alguna vez "te amo"? ¿Te dije alguna vez "te amo"? Difícil reconocerte (Eielson, 1971: 33-34)". El presentimiento de que Eduardo no ha podido reconocer el estado de la relación que mantuvo con la joven italiana no es necesariamente el enigma que esconden estas preguntas. Al realizarse tales interrogantes, aquello que surge es el reconocimiento de la poca necesidad o inutilidad de definir el amor entre ambos personajes. Es como si ante el amor, otrora plurisignificativo e inabarcable, la palabra debiera ser suspendida o no tuviera la necesidad de ser dicha si es que su efecto es una validación ("¿Me dijiste alguna vez "te amo"? ¿Te dije alguna vez "te amo"?"). Quizá por eso, en la espesura de estos amantes, el doble rasero y la condición retórica de la pregunta "¿Qué cosa fuimos?" es una necesidad impuesta por un agente normalizador externo como el comisario que investiga la muerte de Giulia. Ante él, Eduardo se haya más confrontado pues se ve en la obligación de atrapar o encasillar su relación y otorgarle una etiqueta social: “¿Es usted pariente, esposo, novio, prometido, amigo?” (1971: 119), cuando anteriormente, al parecer, no había existido necesidad alguna de explicarlo con palabras porque solo vivía las sensaciones con el cuerpo. De esta manera, "¿Qué cosa fuimos?" es una pregunta que posee el eco de una necesidad por definir la 
relación de la pareja, pero también el reconocimiento de su carácter inefable o inexplicable, en cualquiera de los casos, la respuesta no existe, solo la formulación de más preguntas.

A partir de estas marcas, podríamos dar cuenta que para Eielson existen experiencias que se sustraen al lenguaje, el amor parece ser una de ellas. En ese sentido, el lenguaje no se vincula con el amor para representarlo, sino para representarse en él. Como se evidencia en la novela, esta voluntad no comulga con el imperativo externo, social, que al precisar su definición busca, inversamente, su anclaje. Slavoj Zizek refería que el lenguaje es simbolización, aquello que escapa de esto o se resiste se encuentra en el dominio de lo real que proviene del futuro porque aún no ha sido simbolizado $(2003: 88)^{9}$. La muerte de Giulia ha lanzado a Eduardo al orden simbólico donde el comisario se convierte en una extensión invasiva y violenta. Es quizá esta la razón por la que el protagonista, al saberse saturado y conminado a rendir explicaciones en palabras, sobre todo definiciones, empieza a desmontar su artificio:

Empleo sólo las palabras y las letras necesarias en estas páginas. Pretendo que ellas sean la imagen fiel de mis antecedentes y mis errores desde que te conocí hasta el día de tu muerte. He escogido ese momento no tanto por su grandiosidad, sino porque él es para mí un punto de apoyo capital en este recuento. [...] No puedo desvirtuarlo con el pretexto de un milagro, de una revelación llameante que en realidad no tuvo lugar. Podría escribir: "Yo te amaba, Pajarito, lo descubrí ante tu cuerpo inmóvil, en la Morgue de Venecia." Pero sería falso. (Eielson, 1971: 118)

Resulta notoria la manera en la que Eduardo divaga y duda sobre la capacidad de la palabra. Es una esperanza que termina en decepción pues ellas no contienen "la imagen fiel" de sus antecedentes, por eso, decir "te amo", por ejemplo, se convierte en un acto fallido y contrario a la verdad porque es una formulación de palabras que ha aterrizado lo que estaba o debía estar elevado, el amor, o más bien que lo separa de lo real o de la experiencia física. Será acaso lo mismo que se pregunta Alejandra Pizarnik en el poema "En esta noche, en este mundo" cuando en unos versos escribe lo siguiente:

no
palabras
no hacen el amor
hacen la ausencia
si digo agua ¿beberé?
si digo pan ¿comeré?
(Pizarnik, 1971)

Para Pizarnik, las palabras esconden desaparición, vacío o silencio, a su vez, son la prueba de que nos alejan también de una experiencia física (beber, comer). ¿Es posible releer el fragmento de Eielson con esta condición?: si digo "Yo te amaba", ¿será la prueba de que te amé?, o mejor aún, si digo "Yo te amaba", ¿será la prueba que nuestros cuerpos se amaron? Es seguro que la repuesta negativa y la consciencia de su imposibilidad sume a los poetas en una posición de desconfianza y reclamo que tensiona y torna más compleja su relación con la palabra; esta, según evidencian, ejerce ocultamiento y distancia, por lo tanto, todo lo que ella enuncie es falso: no se come, no se bebe, no se ama. Además de lo señalado, no es la única dimensión en la cual Eielson reitera su cuestionamiento, en El cuerpo de Giulia-no, la palabra recibe una carga adversa que se convierte en la inscripción social de su reiterada crítica. Luego de descubrir su nivel de falsedad, Eduardo empieza a dotar las palabras de aversión y hostilidad: "Empleo, por lo tanto, sólo palabras y letras blancas. Letras odiosamente lógicas, inexpresivas, letras de la prosa, de las cartas comerciales y las noticias diarias. Letras para conversar de política y deportes en los bares. Odiosas letras impresas cuyo veneno es la razón, el orden, la discriminación social, la guerra, las ideologías, el mal" (Eielson, 1971: 118). Si una de las funciones del lenguaje es la de comunicar, las palabras "odiosas" perturban su amor porque son el medio con el cual también se comunica lo tórrido y terrible del mundo, los intercambios capitalistas y las banalidades diarias. Tras estas formas de desdeñar la palabra, lo que subyace en la escala valorativa de Eduardo son ideas heredadas de la guerra o una decepción asumida después de esta que resuena en la novela

${ }^{9}$ Zizek señala que todo lo que ha sido simbolizado se convierte en materia histórica, mientras que el contenido reprimido proviene del futuro. Esto quiere decir que aquello que no está contemplado en la simbolización, pasado, se encuentra en el dominio de lo real, futuro (2003: 88). 
de Eielson. George (Enaudeau, 1999: 27) señalaba que la revolución lingüística del siglo XX, que contempla corrientes de pensamiento filosófico, matemático y movimientos de estudios metodológicos, surge también del análisis de las posibilidades instrumentales del lenguaje descubiertas a raíz del desmoronamiento de los valores humanísticos de 1914, las cuales provocaron una crisis profunda de confianza (Steiner, 2002: 145). De acuerdo con esto, las palabras causan desconfianza y generan hostilidad porque se ha gestado la consciencia de que ellas han sido o pueden ser mensajeras de la guerra, y en general del mal, situación que desarticula y divide el mundo. Se infiere que para Eduardo un motivo más para sustraer del lenguaje su vínculo con Giulia es que las situaciones aludidas, que le generan sospecha, no se encuentran a la medida de la dimensión alada con la cual la ha revestido. El protagonista de Eielson ha sido configurado con un nivel de susceptibilidad con respecto a esta referencia externa que así como le permite cuestionar, también le permite percibir el carácter instrumental y normalizador de la palabra. En este sentido, Eduardo, en su práctica y sensibilidad, refractaría esta consciencia externa o la marca de la "función mundo" del lenguaje (Lyotard, 1979: 96) ${ }^{10}$.

Para Eielson el lenguaje esconde atributos de falsedad y desconfianza que por lapsos aparentan ser espirales sin salida. Es llamativa la manera cómo estos mecanismos son descubiertos a partir de intercambios comunes, más aún, motivados por situaciones cotidianas que así como son emociones también resultan ser construcciones de la palabra.

\section{La materialidad del lenguaje en Primera muerte de María}

Hacia la década de 1980, Jorge Eduardo Eielson escribe Primera muerte de María (1988), su segunda novela. Antes de esta producción narrativa, un poema del mismo título escrito en 1949 delineaba parte de la historia y personajes desarrollados después. Si bien no puede igualarse a la novela de 1988, el poema nos permite identificar la existencia de un antecedente o un plan de escritura posterior que surge en la historia contada en dicha pieza ${ }^{11}$. A esto se refiere el hecho de que el texto narrativo articula tres historias enlazadas mediante la figura de María Magdalena Pacheco (María) o también denominada Lady Ciclotrón, protagonista del poema y de la novela. Una de ellas se desarrolla entre la ciudad y el mar a partir de un grupo de pescadores que, al verse impedidos de seguir subsistiendo de los recursos marinos, atraviesan una Lima derruida por la arena con el propósito de validar sus reclamos ante el ministro. En este contexto aparecen los jóvenes pescadores Pedro y José (nombres de reminiscencias bíblicas así como María), alentados por una turba de reclamos, pero perdidos en la masa citadina y en la procesión, que el autor denomina "océano violeta". Pedro y José son sujetos marinos, es decir, están adheridos estrechamente al mar, y también a la arena, "océano turquesa" y "océano dorado" respectivamente; a pesar de esta vinculación milenaria e íntima con estos elementos, el narrador los configura como personajes opuestos en sus diversas prácticas alrededor del texto. La otra historia desarrollada en paralelo posee el aliento de Lima antigua y clasista en la figura de doña Paquita y su hijo Roberto quien sufre la incomprensión social de la relación que mantiene con su novia de orígenes modestos. En ambas historias, María transita humilde y seductora, es la niña mulata del callejón de Malambo, creyente del Señor de los Milagros; también, es la relación rechazada de Roberto; y es la esposa del pescador José y la primera amante de su amigo Pedro. Sin embargo, entre estas representaciones, María Magdalena Pacheco es además Lady ciclotrón, la joven bailarina del California que todas las noches se desviste y deshace de su atuendo violeta como si se deshiciera de su propia piel. Su strip tease, seguido atentamente por el narrador, es recogido y distribuido por orden de importancia en los títulos de varios capítulos de la novela como si de ese modo estuviera recogiendo pieza por pieza todo el atuendo de la joven (Los guantes, La estola de plumas de avestruz, El traje de satén violeta, entre otros). La historia alternada espacial y temporalmente de María será el tercer elemento que se entrecruza en el texto. Adicionalmente, Primera muerte de María intercala en su corpus diarios escritos por el autor desde los cuales reflexiona, plantea y discute ideas sobre el proceso de escritura y la representación de la palabra; así como, la predilección del autor por el mar, la arena, la ropa y la desnudez. En los diarios, el autor se detiene en su

\footnotetext{
${ }^{10}$ De acuerdo con Jean-François Lyotard, el mundo es una función del lenguaje en el que la palabra "constituye lo que designa en mundo, en objeto denso que hay que sintetizar" (1979: 96).

${ }^{11}$ El poema "Primera muerte de María" de 1949 plantea una historia con un conflicto evidente, María, pobre y débil, muere tras dar a luz al hijo de su esposo quien la poseyó como un caballo sediento. La tendencia narrativa de este poema hace presagiar una historia suspendida con personajes que, a partir de sus profusas características, plantean una necesidad de ser desarrollados.
} 
actividad plástica y en la condición material de los elementos incluidos en la novela como la ropa o la arena. Se trata entonces de una novela compleja que nos plantea diversos caminos de ingreso, sobre los cuales intentaremos articular y dimensionarlos desde la perspectiva del lenguaje.

A diferencia de El cuerpo de Giulia-no, en Primera muerte de María el narrador es heterodiegético, construye la diégesis, pero se mantiene al margen de esta, y menos participa a través de la primera persona. Sin embargo, similarmente a la primera novela, se reiterarán pasajes en los que la consciencia del lenguaje queda expuesta. Aunque, la frecuencia no es la misma, diversa y numerosa como en la historia de Giulia y Eduardo, consideramos que esta pasará al otro lado de la frontera donde los diarios se afirman (volveremos a esta idea en líneas posteriores). En la segunda novela de Eielson, el cuerpo también es materia poderosa, articula la historia, así como el relato, sobre el cual se puede inscribir un tipo de lenguaje escrito. Por ejemplo, en su strip tease, Lady Ciclotrón se quita los guantes y descubre su cuerpo con cicatrices: "Nadie sabría nunca lo que sus manos escondían bajo esos guantes. Ni siquiera cuando las mismas, desnudas, con las palmas encarnadas, mostraban - como una dolorosa escritura- las cicatrices de su pobre infancia" (Eielson, 1988: 13-14). No es muy difícil descubrir el símil que realiza Eielson entre estas marcas físicas y la escritura, lo que nos obligaría a relegar ambas figuras como formas de inscripción para virar hacia la superficie sobre la que se imprimen. Para Eielson, el cuerpo es una superficie física, como la hoja de papel en blanco que espera ser acotada por la tinta, pero es también la posibilidad de otorgarle materialidad al lenguaje escrito o hacer que de la escritura surja una condición material. Plantear la escritura de esta manera ("una dolorosa escritura") incluso lograría evidenciar cómo estas marcas llevan consigo una carga emocional intransmisible o incomunicable de otro modo sea el dolor o la pesadumbre de la infancia de María. Consideramos que una situación similar se produce, y suscribe las ideas anteriores, ya no en el ámbito de la ficción, sino en el diario del 11 de septiembre de 1980 donde directamente el autor se detiene y dirige su atención hacia la arena, otro elemento material insistente en la novela:

Ella ha sido, durante mi breve infancia (casi no la recuerdo) y mi larga adolescencia playera, gozoso escenario de mis juegos marinos, gimnasio natural de mis primeros músculos, mi primera paja, mis primeros versos (escritos en la arena), que ni las olas ni el tiempo han borrado todavía [...] Sólo más tarde comprendería que esa misma arena -siempre hollada por la planta de mis pies y mis versos de niño- era también un inmenso lienzo tendido sobre la faz dorada de mis antepasados. (71-72)

La arena, materia persistente desde la infancia, se convierte para Eielson en la superficie física proclive a la escritura. Así como el cuerpo, sobre ella se inscribirán versos obrados con el mismo ejercicio manual que también reproduce la masturbación ("mi primera paja"), una imagen de raigambre vallejiana: "Quiero escribir / pero me sale espuma" (Vallejo, 2002: 270). Es quizá esta reminiscencia a Vallejo la mejor forma de contemplar la escritura en toda su expresión física, acaso anhelada por Eielson. Escribir en la arena no solo comunicaría lo intransmisible, a este atributo se adiciona su perdurabilidad, ya que las marcas sobre ella la reconocen como una superficie totalizadora ("inmenso lienzo") depositaria de memoria de un pasado cercano y remoto que, así como cubre y se deja moldear, también es imperturbable por el tiempo y el mar. Una formulación previa de esta idea podría ser lo trabajado por Eielson en 1977 en las piezas mixtas "Arena” y "Poema", parangón plástico en el cual la arena se apropia de las condiciones del lienzo para permitir la escritura de palabras y la manifestación de la fuerza y manipulación humana. 


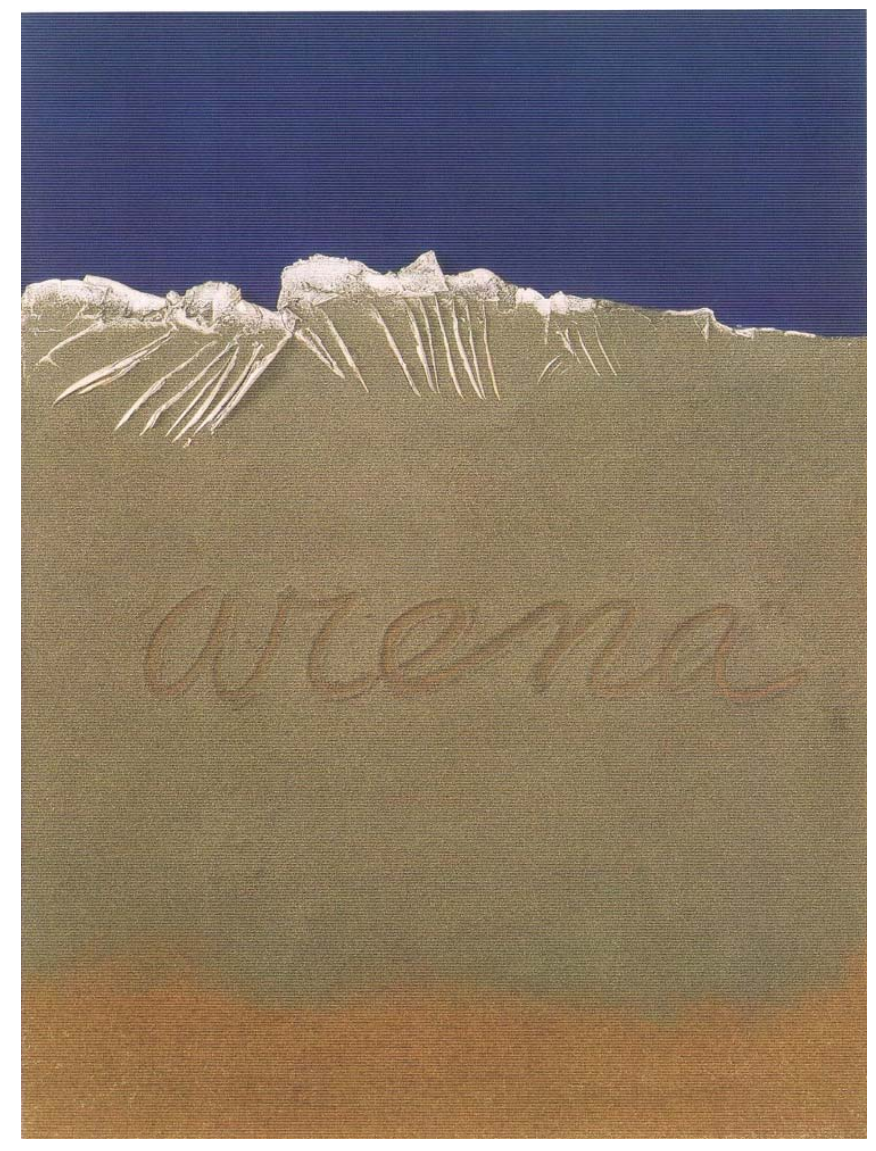

Jorge Eduardo Eielson. Arena (1977)

Técnica mixta sobre tela $130 \times 97 \mathrm{~cm}$.

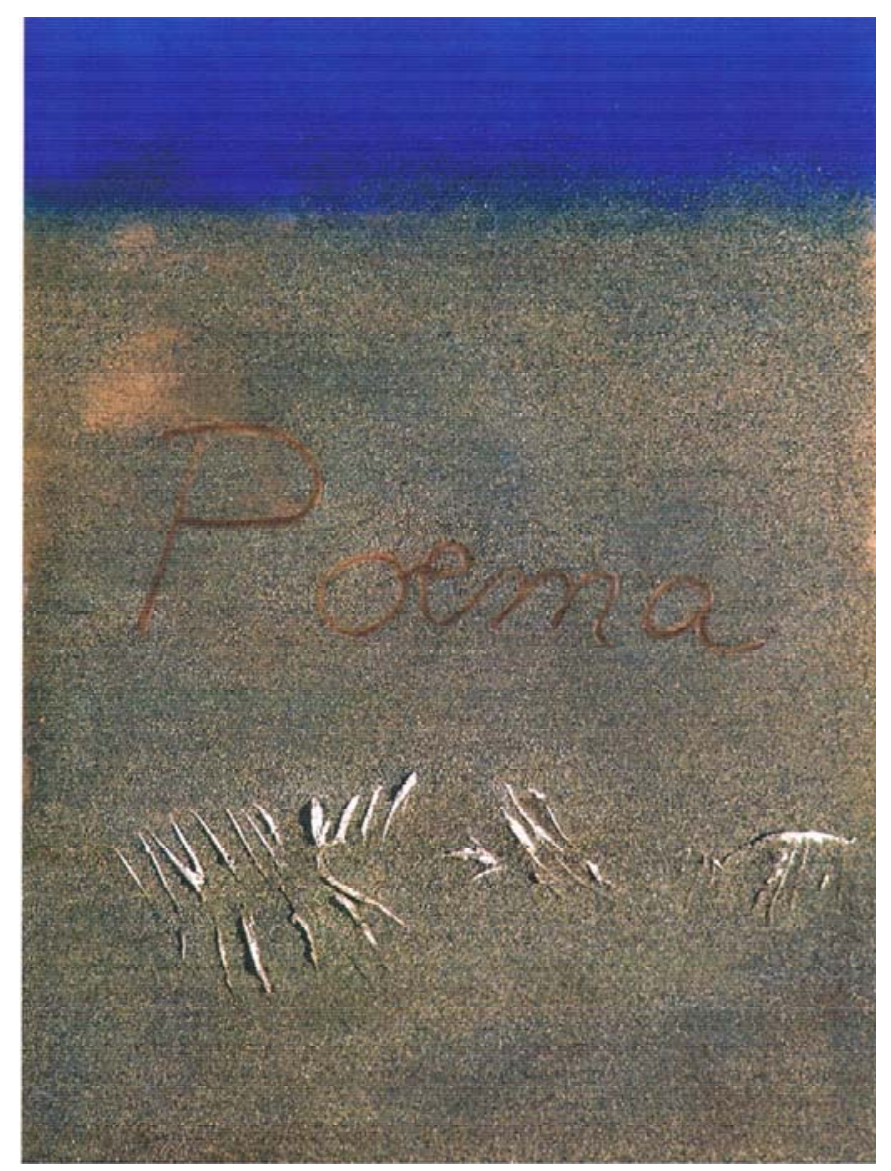


Pero esta manera de desentrañar la arena en el discurso y en el antecedente plástico, no nos sitúa precisamente en una correspondencia literal, tan cara en la obra de Eielson, más sí nos gustaría pensarla como un posible eslabón que expresa la importancia que va adquiriendo la condición material de la palabra, y en general la materialidad.

En esta dirección se orientaría el diario del 17 de septiembre de 1980. En él Eielson relata los quiebres en la representación de la palabra que generó en su escritura la historia de los pescadores desolados en la costa peruana, vislumbrada en su momento de exilio: "Lo que más me urgía -o así me parecía- era la representación del paisaje por la palabra. Pero sin caer en la simple descripción, ni el puro lirismo" (Eielso, 1988: 75). La pregunta emergente sería ¿por qué Eielson no desea solo describir con la palabra?, o en todo caso ¿por qué antes de la palabra este menciona la representación? En un pie de página que subyace a estos apuntes, el autor precisa con detenimiento por qué prescindir de la palabra se convierte en una opción para construir su texto:

Sólo más tarde comprendí que los materiales que yo necesitaba para ese añorado texto, no eran palabras. Es decir, no eran los personajes (aunque ellos deberían regresar más tarde, reducidos a simples vestidos), ni los sentimientos ni las circunstancias que los movían, sino simplemente los colores, el espacio, las texturas. Pero, sobre todo, el espacio, puesto que era el espacio - el elemento más sutil del paisaje - el que rodeaba, en un estéril abrazo, la ciudad en que nací. (1988: 75)

La novela, de por sí escrita con palabras, porta consigo un vínculo tenso y una apertura hacia la materialidad; a pesar de esto, las historias entrecruzadas resultan inteligibles y claras, muchos tramos incluso con deudas claves en su poesía de la década del 50. Son estos aspectos por los que consideramos que Primera muerte de María está más cercana o encaminada a ser un proyecto antecesor o un boceto revelador de otro proyecto presuntamente plástico ${ }^{12}$ o al menos, así parece dar por sentado la intervención del diario: no personajes, sino vestidos; no sentimientos, sino colores, espacio y textura. Eielson hace de su novela un boceto, no un guion, porque la representación por la palabra le resulta dudosa o una paradoja que, como señala Corine Enaudeau, posee transparencia porque ella se borra ante lo que muestra, pero también opacidad pues solo se representa a sí misma presentando la cosa (Enaudeau, 1999: 27). Por eso el autor desea "ir a las cosas mismas sin las palabras", pero a través de los materiales que alude en los diarios. Este espíritu, que horada su novela, arma los cimientos de una obra plástica, y al mismo tiempo critica la representación para "reencontrar la inscripción de la verdad" (1999: 30) que será finalmente su infancia y adolescencia enterradas o escritas en la arena. Los pedazos de materia o "materia pictórica" se tornan fragmentos de memoria para el artista de los que solo importa su "verdad" y con los que conformaría, según su testimonio, "ese paisaje virtual que las palabras nunca podrían devolverme" (Eielson, 1988: 75); es decir, no paradoja, no distanciamiento, menos opacidad, sino la materia misma. La confesión final del extenso pie de página del diario del 17 de septiembre sería la creación, paralela a Primera muerte de María, de la serie Paisaje infinito de la costa del Perú ${ }^{13}$, ciertamente, la realización plástica de todo lo apuntado en el boceto-novela.

Como hemos ido adelantando, en esta novela, los diarios reciben una importancia predominante. Según Maurice Blanchot, el diario es un memorial, no una confesión del escritor, en el cual se recuerda a sí mismo cuando no escribe, cuando vive la vida cotidiana (Blanchot, 2002: 24). De acuerdo con el estudioso, para quien la literatura es entregarse a un tipo de neutralización que disuelve toda posibilidad de relación personal, en el diario, el escritor establece puntos de referencia en los que puede reconocerse cuando presiente la metamorfosis a la que está expuesto con la escritura (2002: 24-25). En la novela de Eielson, los diarios se tornan anclajes en los que sus construcciones literarias son contrastadas con su experiencia personal, no necesariamente como si intentara dejar claro que todo lo representado por las palabras poseyera un correlato de verdad detrás, sino como el preciso testimonio de que su escritura también se encuentra,

${ }^{12}$ Luis Rebaza señala que entre las novelas de Eielson y sus performances se establece una relación de soporte lingüístico. Es decir, son el ancla de las obras plásticas. Nuestra lectura no totaliza este enfoque porque Primera muerte de María no es necesariamente un soporte lingüístico, pero sí un boceto.

${ }^{13}$ Entre 1960 y 1980, Jorge Eduardo Eielson produce una serie de cuadros "matéricos" que aluden a la costa y el mar peruano a partir de la integración en el lienzo de elementos como arena, ropa o restos óseos. En alusión a sus orígenes peruanos, denomina a esta serie Paisaje infinito de la costa del Perú. Un ejemplo de este conjunto de lienzos son los anteriormente citados Arena y Poema de 1977. 
como reflexiona Blanchot, arraigada en el tiempo, en la humanidad y en lo cotidiano fechado $(25)^{14}$. Por un lado, destacan los diarios en los que relata las experiencias que sirvieron como telón de fondo a la escritura de Primera muerta de María: su exilio, la luxación de su tobillo derecho en el verano de 1960, sus radiantes mañanas mediterráneas o la gestación de sus series artísticas. Por otro lado, se encuentran los recuentos de las experiencias vinculadas con la ficción misma de la novela. Esto es lo ocurrido incipientemente, por ejemplo, en el diario del 22 de agosto de 1980:

Mientras escribía e imaginaba (Roma, 1960) lo que podría ser la procesión del Señor de los Milagros en la ciudad de Lima, en un lejano futuro, no tenía a mi alcance sino las imágenes borrosas de mi memoria, que yo intentaba proyectar en dicho futuro. [...] La marea humana que me envuelve, las calles oscuras y siniestras, las lamentaciones, los estragos del alcohol, la miseria y la droga ¿no serán más bien realidades surgidas del texto? (Eielson, 1988: 27)

El diario le permite retornar a los episodios en los que personajes, acciones e historias eran memoria manifestada en una ciudad europea de la década del 60. En este registro del tiempo, las imágenes borrosas de la memoria no alimentan una frecuencia uniforme para Eielson, ellas se confunden con la realidad que brota del texto como si este no pudiera controlar la marea de lo que Martín Lienhard, al analizar los diarios de José María Arguedas, denomina "conciencia-de-la-obra-de-ser-literatura" que toda intervención del autor le imprime a su obra (Lienhard, 1981: 31) ${ }^{15}$. El diario es en efecto un testimonio, pero proclive también a ser el seguimiento de la formación de esa "conciencia" de ser literatura o el reconocimiento de que algunos pasajes se van convirtiendo en no miméticos. Quizá por eso los diarios posteriores, como el del 26 de agosto y el 11 de septiembre del mismo año, encarnan en un grado mayor de preocupación en Eielson por el vínculo que va perdiendo con los pasajes de su experiencia personal en manos de lo literario. Tal es el caso de la forma en la que se expresa de Lady Ciclotrón:

Como toda invención literaria, Lady Ciclotrón adolece de un defecto: ella ha existido realmente. [...] Hubiera querido escribir sobre ella como si cantara. Hubiera sido un himno. [...] Casi sin palabras. Esto no me ha sido posible. Pero, si la he rodeado de gente, de personajes abyecto, de amores absurdos, de humillaciones, de palabras, es porque yo mismo [...] yo mismo nunca la comprendí. (Eielson, 1988: 37)

De acuerdo con el autor, la condición de literariedad es la existencia real de su objeto de representación que, al no poder ser representado de otra manera que no sea el lenguaje (un canto o un himno), es sometido a un rodeo de palabras. En este sentido, "la conciencia de ser literatura", presente en los diarios, es también la consciencia ${ }^{16}$ del lenguaje, de cómo este se retira del curso del mundo, el que nadie habla y el que no se dirige a nadie, y donde el escritor renuncia a decir "Yo" a favor de la construcción de su obra literaria (Blanchot, 2002: 22).

Al ser el diario un espacio de testimonio que intercala grandes segmentos de la narración, consideramos que en este se manifiesta y representa el llamado de Eielson por no dejar de ser histórico. Con esto nos referimos a que quien escribe todavía desea pertenecer al tiempo donde el lenguaje no lo distancia de sus fragmentos de verdad, esos que en el citado diario del 17 de septiembre le permiten regresar y pertenecer, como señala, a un espacio, instante, ritmo e inefable latido que se había vuelto objeto de veneración (Eielson, 1988: 76), sea la arena, como también el mar. Afirmarse a la materialidad sería para Eielson aquello que otorga la posibilidad de ser histórico, la existencia real y comprobada de que el lenguaje en la literatura neutraliza y despersonaliza. Esto descubriría a los diarios como un terreno o discurso proclive a la enunciación y alusión de los proyectos plásticos que Eielson desarrolló a partir de la materialidad de la arena o la ropa. Dos ejemplos pueden ser citados para este caso. El primero de ellos es el testimoniado en el diario del 19 de septiembre de 1980. Después de la muerte de Marilyn Monroe, personaje ocasional en Primera

\footnotetext{
${ }^{14}$ Para Sergio Ramírez Franco los diarios de Eielson constituyen un metatexto que adopta del arte moderno, específicamente de Duchamp, la dialéctica que presenta una obra con su propio comentario (2001: 70).

15 Según Martín Lienhard, en una obra la "intervención del autor" le imprime a esta un sello de literariedad o de "conciencia-de-la-obra-de-serliteratura" (1981: 31). Para Lienhard, a través de los diarios, un autor busca un efecto de distanciación entre el lector y la obra; al mismo tiempo, el reconocimiento de su carácter no mimético.

${ }^{16}$ Siguiendo a Adam Zeman (2009), quisiéramos entender la consciencia como el hecho de estar conscientes, es decir, estar ubicados de forma activa en una realidad y con la consideración de que un asunto ha sido compartido previamente con nosotros mismos en nuestras intenciones y propósitos.
} 
muerte de María, el autor relata la forma en la que durante su serie matérica, en los diversos tipos de materiales trabajados, entre ellos un sostén senos y una fotografía, surgió la actriz estadounidense como un personaje, resto o despojo absorto (1988: 82). Esta es una clara alusión a "Réquiem por Marilyn Monroe" (1962), ensamblaje de lienzo y ropaje en el cual se homenajea la presencia y la ausencia de la fallecida actriz.

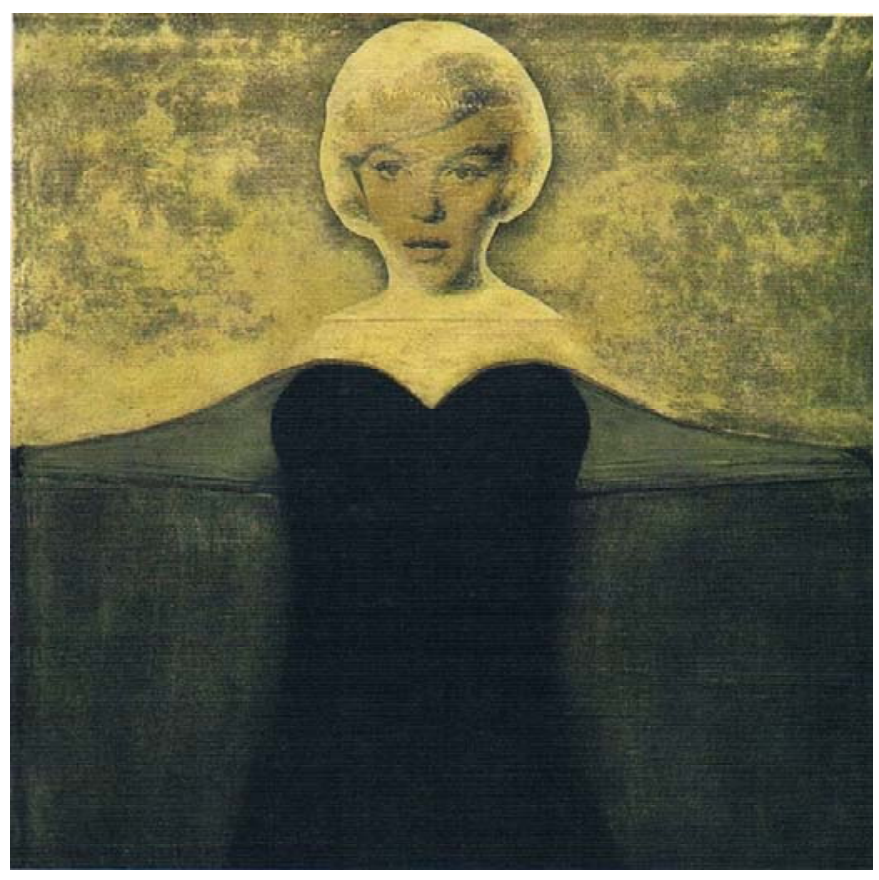

Jorge Eduardo Eielson. Réquiem por Marilyn Monroe (1962)

El segundo ejemplo se trata de la nota al pie del diario del 8 de octubre de 1980 en donde Eielson, tras su distancia y deseo de mostrar la miseria de la ciudad, precisa que su verdadera tentativa no era escribir una novela sino la composición de un espectáculo escrito que más tarde podría realizar en forma de performances (Eielson 1988: 101). El comentario se refiere a la performance e instalación denominadas "Interrupción" y "Primera muerte de María" (1988), obras que emplean el cuerpo, la arena y objetos cotidianos en su ejecución.

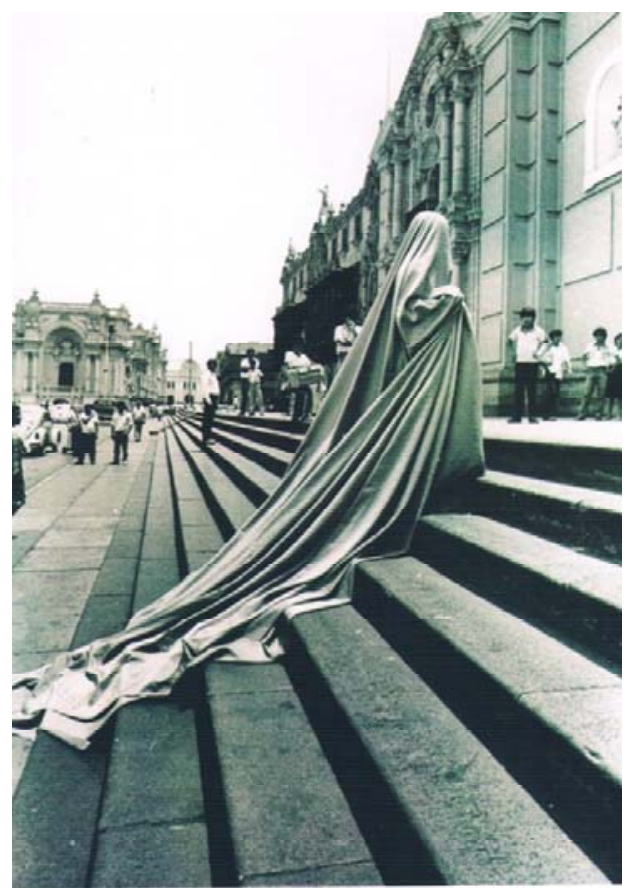

Jorge Eduardo Eielson. Interrupción (1988). Performance. Lima. 
En ambos casos persistirá la voluntad del autor por enlazar su escritura con la plástica como deseando no desvincularse de un espacio tiempo suspendido por la literatura. La misma voluntad para la cual la introducción de los diarios se convierte en un recurso necesario, ya que se convierte en un anclaje del lenguaje.

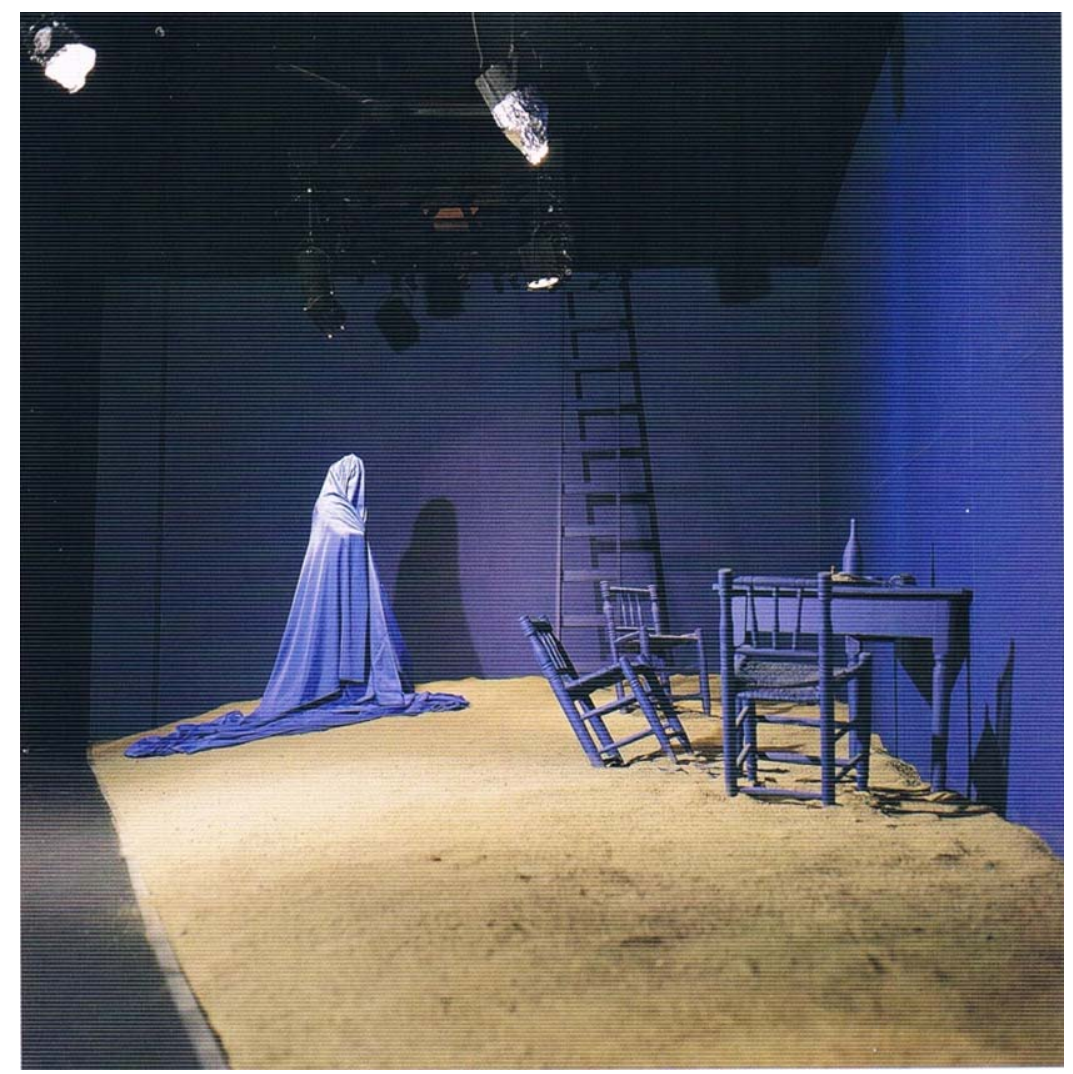

Jorge Eduardo Eielson. Primera muerte de María (1988). Performance. Lima

\section{Conclusión}

Nuestro análisis ha podido evidenciar de qué manera la novelística de Jorge Eduardo Eielson asume un claro conocimiento reflexivo sobre el lenguaje a partir de dos aspectos. El primero, en El cuerpo de Giuliano, asume operaciones que visitan los valores lingüísticos propios de la revolución lingüística del siglo XX. En ese sentido, el personaje conductor de esta consciencia en la novela, Eduardo, posee una agencia que le permite identificar la condición desvirtuadora de lo metafísico y no traducible del lenguaje a partir de su vínculo amoroso con la desaparecida Giulia, agente ocasionador de su cuestionamiento. En el segundo caso, en Primera muerte de María, desde el cuestionamiento anterior, el autor ejerce un vínculo entre la escritura de su novela y sus obras plásticas como anclaje de aquella realidad, o ser histórico, que se desvanece con la palabra. En ambos casos, el cuestionamiento a la representación transita por un pleno conocimiento de sus mecanismos hasta proponer una necesaria escritura en el cuerpo o asumir la materialidad como el resquicio donde pueda pervivir la experiencia arrebatada por el lenguaje.

\section{Referencias bibliográficas}

Eielson, Jorge Eduardo (1971). El cuerpo de Giulia-no. México D. F.: Editorial Joaquín Mortiz. (1988). Primera muerte de María. México D. F.: Fondo de Cultura Económica.

Blanchot, Maurice (2002). El espacio literario. Madrid: Editora Nacional.

Enaudeau, Corine (1999). La paradoja de la representación. Buenos Aires: Paidós.

Lienhard, Martin (1981). Cultura popular andina y forma novelesca: zorros y danzantes en la última novela de Arguedas. Lima: Tarea/Latinoamericana Editores.

Lyotard, Jean-François (1979). Discurso, Figura. Barcelona: Editorial Gustavo Gili. 
Minardi, Giovanna (2016), “Jorge Eduardo Eielson y Julio Ramón Ribeyro: Dos narradores de la generación del 50 y su visión de Lima”, en Sandro Chiri y Javier de Taboada (eds.). Palabra, color, imagen y materia en la obra de Jorge Eduardo Eielson. Lima: Casa de la Literatura Peruana/Animal de invierno, págs. 107-116.

Pizarnik, Alejandra (1971), "En esta noche, en este mundo", en Árbol de Fuego.

Ramírez, Sergio (2001). A favor de la esfinge La novelística de j.e. eielson. Lima: Fondo editorial UNMSM.

Saussure, Ferdinand de (1945). Curso de lingüística general. Buenos Aires: Editorial Losada.

Steiner, George (2002). Extraterritorial Ensayos sobre literatura y la revolución lingüística. Madrid: Siruela.

Vallejo, César (2002). Obra poética César Vallejo. Lima: Ediciones Peisa.

Wittgenstein, Ludwig (1976). Los cuadernos azul y marrón. Madrid: Editorial Tecnos.

Zeman, Adam (2009). La consciencia. México D. F.: Fondo de Cultura Económica.

Zizek, Slavoj (2003). El sublime objeto de la ideología. Buenos Aires: Siglo XXI Editores. 